\title{
The development and in vitro evaluation of benzydamine hydrochloride medicated chewing gum formulations
}

\author{
Özlem Akbal*, Erdal Cevher, Ahmet Oğul Araman \\ Department of Pharmaceutical Technology, Faculty of Pharmacy, İstanbul University, 34116, İstanbul, Turkey
}

Cite this article as: Akbal Ö, Cevher E, Araman A (2017). The development and in vitro evaluation of benzydamine hydrochloride medicated chewing gum formulations. Istanbul J Pharm 47 (2): 45-51.

\begin{abstract}
The objective of this study was to develop a chewing gum formulation for benzydamine hydrochloride (BN) and evaluate the effect of different co-compression agents on physicochemical parameters and in vitro drug release profile. BN has been utilized in symptomatic treatment for pain and irritations of the mouth and throat. Chewing gum formulations of BN were produced using direct compression method. In fabricated chewing gums, except pharmacopeia analysis, physical and structural analysis like thickness, weight variation, elasticity and compressibility were evaluated. The release of BN from the gum was studied using the chewing apparatus which have been designed for procuring the release of BN from the chewing gum. The quantity of BN present in the chewing gum and the release medium were quantified by spectrophotometric method. Gum formulations showed promising in vitro release profiles, in which $80-$ $90 \% \mathrm{BN}$ was released in a sustained manner over $20 \mathrm{~min}$ of chewing time. In addition, it was observed that the drug release was fitted into matrix diffusion kinetic and revealed a non-Fickian drug release mechanism. This study suggests that $\mathrm{BN}$ in a gum formulation is a suitable dosage form for the delivery in the oral cavity, thereby and serving as an instant analgesic.
\end{abstract}

Keywords: Benzydamine hydrochloride, medicated chewing gum, mastication apparatus

\section{INTRODUCTION}

Benzydamine hydrochloride (BN), a tertiary amine derivative, is a non-steroidal anti-inflammatory agent that possesses analgesic, anesthetic, anti-inflammatory, anti-pyretic and anti-microbial properties. However its oral, topical and oro-mucosal dosage forms are currently available in the market, it is commonly in use for the relief of inflammatory conditions of the oral cavity soft tissues and skin.

In a mouth-rinse formulation as a concentration of $0.15 \% \mathrm{BN}$, its use has been indicated in the cure for recurring oral disorders as aphthous stomatitis, burning mouth syndrome, sore throat and radiation-induced oral mucositis (Herrera 2005).

Since the ancient times, chewing gum has been used world-wide, however the concept of using chewing gum as a drug delivery system has been implemented for more than 100 years. Aspergum, which contains acetyl salicylic acid, is the first medical chewing gum (Noehr-Jensen et al. 2006). It was marketed in 1924 in the USA and is still in the market. Chewing gums gained broader attention as a drug delivery system with the introduction of nicotine containing chewing gums into the market in 1978 (Rowe 2003). Twenty years later, in 1998, drug containing chewing gums were included in the European Pharmacopoeia with the name: 'medicated chewing gum' (European Pharmacopoeia $9^{\text {th }}$ edition ).

The definition of medicated chewing gum in the European Pharmacopoeia is stated as; "a single-dose, solid preparation with tasteless masticatory gum base, mainly consisting of gum which is intended to be chewed and not swallowed, providing a slow steady release of the medicine contained", and it is intended to be used as "local treatment of mouth diseases or systemic delivery after absorption through the buccal mucosa or from the gastrointestinal tract" (Herrera 2005). Medical chewing gums have 
been formulated with different kinds of drugs beside nicotine (Cherukuri et al. 2000; Morjaria et al. 2009) and aspirin (Woodford and Lesko 1981) such as nystatin (Andersen et al. 1990), miconazole (Pedersen and Rassing 1990), caffeine (Tyrpin et al. 2002), antacids (Zyck et al. 2003), anti-microbial decapeptide (Dong et al. 2005), ondansetron hydrochloride (Nagaich et al. 2010), cetirizine (Stojanov et al. 2012; Swamy et al. 2012), dextromethorphan hydrobromide (Swamy et al. 2012), dimenhydrinate hydrochloride (Mehta and Trivedi 2011).

Medicated chewing gums have so many benefits compared to other conventional oral mucosal dosage forms that are intended to be used for local treatment of mouth diseases like gingivits and dry mouth sydrome (Maggi et al. 2005). Chewing gums are also useful for providing tooth hygiene and cariesprevention by activating the masseter muscles and stimulating secretion of saliva that contains rich bicarbonate ions, in which increase in plaque $\mathrm{pH}$ reduce the risk of caries formation (Abelson et al. 1990; Dodds et al. 1991). Chewing gum can be retained in oral cavity for long times and with the help of the saliva circulation within the mouth, drug could be effectively distributed inside the whole mouth. As a dosage form, gum could be taken easily and discretely without any need of water intake and also in any case prompt discontinuation of medication is possible. Besides, the use of chewing gum as a drug delivery system can also improve patient acceptance and compliance. In addition to offering clinical benefits, medicated chewing gums have also good physical and chemical stability during the use and the storage as well (Maggi et al. 2005).

Chewing gum consists basically of a neutral and tasteless masticatory gum-base and several non-masticatory ingredients, such as fillers, softeners, sweeteners, flavouring and texture regulating agents (Rassing 1992; Eisenstadt et al. 1998). All excipients in the gum formulation gives different properties to the formulation like anti-sticking effect to the teeth, long lasting flavor and improved texture. After non-sugar gums gain attention, combinations of sorbitol, xylitol, mannitol, aspartame and acesulfame potassium is started to use in sugar free gums and medicated gums (Maggi et al. 2005).

There are three main methods given in the literature which are properly used for production of medicated chewing gums named as; conventional and direct compression method and ion exchange method which is specialized for nicotine containing chewing gum. Among these three methods, direct compression which is developed in compliance with the conventional tablet compression technology brought advantages as; the easiness of production steps, cost and time effectiveness, by using low temperatures allows us to use sensitive bioactive and phytochemical components by this way it can prevent the potential stability problems, low moisture prolong the shelf life of the active in the gum and higher dosage of active could be formulated within gum. However, the main drawback of these methods is the sticking effect of the gum base to the compression punches of the tableting equipment. This problem originates from the adhesive nature of the gum base, major component of the formulation; due to this reason, production speed should be held at slow and cooling proce- dure could be applied optionally. To prevent any sticking problems, whole tableting machines and their tools should be kept at temperatures below $18^{\circ} \mathrm{C}$ during the production process. And it should be noted that the temperature should not be as low to interfere the production procedure of medicated chewing gums therefore the temperature should be held above 10$12^{\circ} \mathrm{C}$ (Testa 1999; Mostafavi et al. 2014).

The recommended solution to overcome the sticking problem is using co-compression agents as glidants and lubricants in different manners but in some formulations it causes organoleptic problems and it could change the release profile of the drug from the chewing gum so it is crucial to find the exact amount for each ingredient in the formulation receipt.

The primary objective of this work was to develop a chewing gum formulation for BN and investigate the influence of different lubricants on physicochemical parameters and drug release profile.

\section{MATERIALS AND METHODS}

\section{Materials}

Benzydamine hydrochloride was a gift sample, provided by Santa Farma (Istanbul, Turkey). Health in Gum, compressible gum base powder mixture was obtained from Cafosa Gum S.A. (Barcelona, Spain) as a sample gift, Colloidal silicon dioxide from Evonik Industries (Germany), and the other chemicals provided as a gift sample from Roquette (France). All the other companents are in the analytical grade.

\section{Methods}

\section{Chewing gum mastication apparatus}

A chewing gum mastication apparatus was designed to simulate the chewing behaviour for the release of benzydamine from the gums. The designated apparatus was used to evaluate the releasing pattern of the drug from gum. Briefly, the fully stainless steel wall of the vessel was used to be able to keep the temparature equal inside the whole vessel during the mastication of gum samples.

The instrumental settings were adjustable for temperature and mastication rate. In the present experiment the following settings and conditions were used. Temperature of the test medium was set at $37^{\circ} \mathrm{C} ; 10 \mathrm{ml}$ of artificial saliva buffer, $\mathrm{pH}$

\section{Table 1. Composition of artificial saliva*}

\begin{tabular}{|lc|}
\hline Composition & Amount $(\mathrm{g} / \mathrm{L})$ \\
\hline Potassium chloride & 0.720 \\
Sodium chloride & 0.600 \\
Calcium chloride dihydrate & 0.220 \\
Citric acid & 0.030 \\
Potassium thiocyanate & 0.060 \\
Potassium bicarbonate & 1.500 \\
Potassium phosphate monobasic & 0.680 \\
Sodium phosphate dibasic & 0.886 \\
\hline * Swamy et al. 2012 & \\
\hline
\end{tabular}


6.75, (Table 1) was used as the volume of the test medium. 50 strokes per minute was implemented for chewing frequency. The distance between the upper and lower jaws set was at 1.6 $\mathrm{mm}$ and total chewing time was $60 \mathrm{~min}$. Aliquots of $1 \mathrm{ml}$ were withdrawn from each time point from the chamber at 0, 5, 10, 15,30 and 60 min during the in vitro releasing procedure. The samples were diluted for analyzing the drug concentrations in the test medium (Kvist et al. 2000).

\section{Spectrophotometric analysis}

Spectrophotometric measurements of BN samples were carried out using the UV-1601 model UV-VIS spectrophotometer with $1 \mathrm{~cm}$ quartz cell. A standard stock solution of BN reference standard $(100 \mu \mathrm{g} / \mathrm{mL})$ was prepared in a $10 \mathrm{~mL}$ calibrated flask in artificial buffer ( $\mathrm{pH}$ 6.75). A validation set, consisting of six solutions in working range of 1-60 $\mu \mathrm{g} / \mathrm{mL}$, was freshly prepared and scanned in UV region. This process was repeated three times for each concentration. The absorption maxima, observed at $308 \mathrm{~nm}$, was recorded and plotted against concentration, which followed the Beer and Lambert's law and gave a straight line $\left(R^{2}=0.9998\right)$.

\section{Preparation of Benzydamine Hydrochloride chewing gum}

Direct compression method was used to produce twenty seven chewing gum powder formulations containing BN. Formulation of chewing gum mainly consisted of gum base powder, fillers, active ingredients (drug), and flavoring agents as shown in Table 2. At the fist stage of production steps, BN was mixed with aspartame- acesulfame potassium (1:2 ratio) as a suitable sweetener by using cubic shaker for 15 min.Then this mixture was directly mixed with compressible gum base powder for another $10 \mathrm{~min}$. Since BN has slightly bitter taste, menthol flavor (0.5\%) was used to mask its bitterness and unpleasant taste. Gum powder mixture which was obtained by adding co-compression agents to previous powder mixture, became ready for compression. Gums were compressed in oval shapes, in every piece of which $2.3 \mathrm{~g}$ of powder was weighed by using Korch EK-0 model hydraulic tablet compression machine. To prevent probable sticking problems, not only whole tableting machines and their tools were kept at temperatures below $18^{\circ} \mathrm{C}$, but also co-compression agents as glidants; colloidal silicon dioxide and lubricants; magnesium stearat in different manners were used during the production process.

\section{Determination of pre-compression parameters}

The formulated chewing gum granules for each formulation in Table 2 were evaluated for pre-compression parameters such as bulk Density $(\mathrm{V} b)$, tapped density $(\mathrm{V} t)$, Hausner's ratio $(H)$ and Carr's Index (I) which are indicative parameters for flow and compressibility (European pharmacopoeia, $9^{\text {th }}$ edition).

$$
\begin{aligned}
& \text { Bulk Density }(V b)=\frac{\text { Mass }}{\text { Bulk Volume }} \\
& \text { Tapped Density }(V t)=\frac{\text { Mass }}{\text { Tapped Volume }} \\
& \text { Hausner's Ratio }(H)=\frac{V t}{V b} \\
& \text { Carr's Index }(I)=\frac{V t-V b}{V t} * 100
\end{aligned}
$$

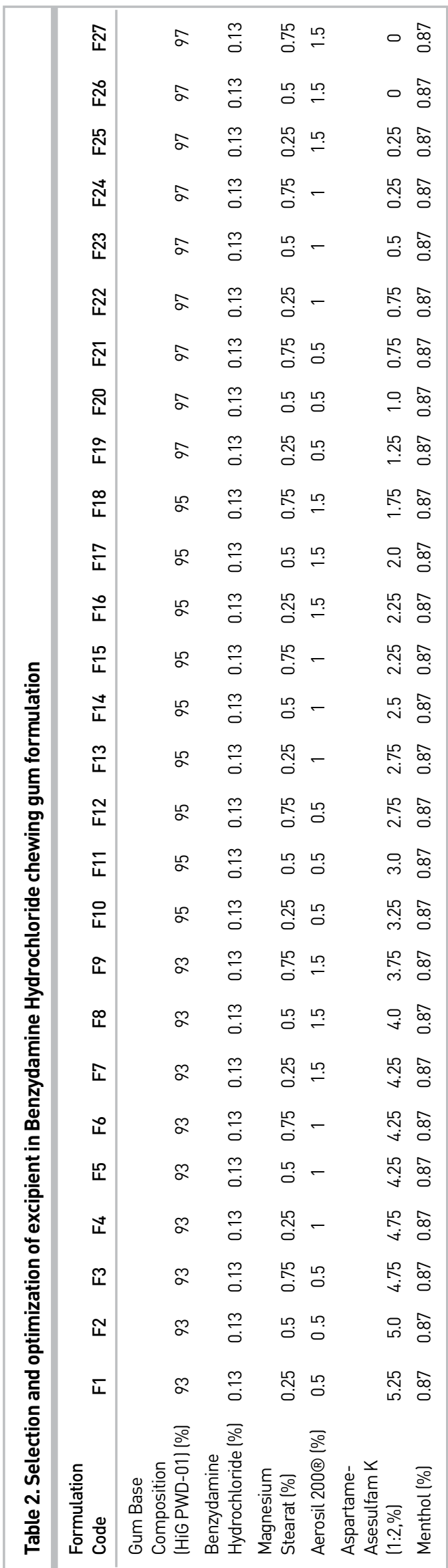




\section{Determination of post-compression parameters}

The chewing gum tablets, shown in Table 2, were subjected to weight variation test ast uniformity of mass and drug content, tablet breaking force/hardness and friability determination.

\section{Uniformity of mass}

Uniformity of mass is mainly implemented for non-coated compressed dosage forms. Ten unit of gums were taken randomly from different gum formulations and weighed individually. The arithmetic mean weight was used to calculate the results. The dosage form formulation comply with the test; on condition that, not more than two of the individual masses deviate more than 5\%, from the average mass (European pharmacopoeia, $9^{\text {th }}$ edition).

\section{Uniformity of drug content}

Ten units of chewing gum from randomly selected formulations from Table 2 were used to determine drug content in prepared chewing gums. Each gum piece was crushed separately and transferred into a $10 \mathrm{~mL}$ volumetric flask and $10 \mathrm{~mL}$ artificial saliva was added. After $1 \mathrm{~h}$ mixing with magnetic stirrer, 1 $\mathrm{mL}$ of sample was taken and diluted with artificial saliva to 10 $\mathrm{mL}$. The absorbance of solution was measured spectrophotometrically at $308 \mathrm{~nm}$. The standard curve was used to calculate BN concentration. The formulation complies with the pharmacopeial test limits, only if the individual drug content result is between $85 \%$ and $115 \%$ of the average content (European pharmacopoeia, $9^{\text {th }}$ edition).

\section{Friability}

To evaluate friability of compresed gums, ten units of gum formulations from the twenty seven formulations were randomly chosen and attentively de-dusted prior to test. Then gums were accurately weighed and placed in the drum of a Sotax HT-1 Friabilator. The drum was rotated 100 times at 25 rpm, and then gums were removed from the drum. Loose dust was removed from the gums as mentioned above and reweighed accurately. The difference in two weights represents the friability of formulation. A maximum loss of mass (obtained from a single test or from the mean of three tests) not greater than $1.0 \%$ is considered admissible (European pharmacopoeia, $9^{\text {th }}$ edition).

\section{In vitro drug release from chewing gum}

The standardized equipment for disintegration, dissolution and drug release testing, used for the conventional oral dosage forms could not be considered as appropriate for the medicated chewing gums because the drug release process from medicated chewing gum is quite different compared to other conventional oral dosage forms fundamentally. For evaluation of the drug release from chewing gum, both of the dosage form and the chewing activity would influence the drug release which should be considered in release studies. Furthermore, gums are not intended to dissolve/disintegrate by themselves so a mechanical force inside the mouth is needed to cause the active release drug from the chewing gum (Liljewall 1992). Therefore,the European Pharmacopoeia guidelines recommend to use of a spesific device for in vitro release studies from medicated gum formulations which is able to simulate the human chewing behavior (European pharmacopoeia, $9^{\text {th }}$ edition). But high cost of the equipment prompt most of the research groups to find alternative solutions as designing new equipment which can fulfil researchers needs (Gajendran et al. 2008).

In the current study, all twenty seven BN chewing gums have been tested by using the mastication apparatus. Artificial saliva $(10 \mathrm{~mL})$ was placed to mouth stimulating part of mastication apparatus and a prepared chewing gum was placed on its predesigned place in the apparatus. The ragged piston, designed to simulate the teeth, was adjusted. The mechanical mixer (as a motor) was attuned on 50 rounds per minute. The masticating apparatus was started to release the drug from the chewing gum by mechanical forces.

Aliquots of $1 \mathrm{ml}$ were withdrawn from each sample at 5, 10, 15, $20,30,40,50$ and $60 \mathrm{~min}$. during the releasing test and diluted to $10 \mathrm{~mL}$ for spectrophotometric analysis. The medium was replaced by an artificial saliva ( $\mathrm{pH} 6.75$ at $37^{\circ} \mathrm{C}$ ) after each sampling. The experiments were replicated with placebo chewing gums as well. The percentage of drug released during the mastication process was calculated by subtracting the absorbance of the active ingredient, present in the gum from the absorbance of the placebo gum.

\section{In vitro drug release kinetics}

For understanding the mechanism of drug release and release rate kinetics of the drug from the dosage form, the obtained data was fitted into the equations belongs to zero order, first order, Higuchi matrix, Krosmeyer \& Peppas model by analyzing the values, the best fit model was selected (Peppas 1985; Swamy et al. 2010)

\section{Influence of co-compression agents on in vitro drug re- lease profile}

In this study, beside keeping the environmental temperature of production below $18^{\circ} \mathrm{C}$, various amounts of co-compression agents were also employed to overcome the sticking problem during the production of the chewing gums. While using cocompression agents in the production, their effect on release profiles should be taken into consideration. Therefore, quantity bound effect of these agents on the release profiles within the study evaluated.

\section{Statistical analysis}

All testing is performed in accordance with the pharmacopoeia requirements. In any cases in which the statistical analyses were required, the paired t-test was performed. A significant difference was $p<0.05$ used.

\section{RESULTS}

Gum formulations were visually inspected and physically evaluated for appearance, color, stickiness, and plasticity, which seem suitable. All gums were prepared in an oval-shape with 2 $\mathrm{cm}$ diameter and $1 \mathrm{~cm}$ thickness and the prepared gums had smooth and soft surface.

The physical parameters of the granules for all the formulated batches exhibited good flow properties, which is indicated by the bulk and tapped density in the range of $0.465 \mathrm{~g} / \mathrm{mL}$ to $0.575 \mathrm{~g} / \mathrm{mL}$ and $0.540 \mathrm{~g} / \mathrm{mL}$ to $0.610 \mathrm{~g} / \mathrm{mL}$ respectively. 
The Carr's index was found to be in the range of $5.263 \%$ to $9.615 \%$ and Hausner's ratio was in the range of $1.044-1.093$, which is found to be acceptable.

The mean weight of 20 chewing gum tablets from each twentyseven formulation were determined. None of the tablets deviated by more than $5 \%$ from the mean weight, indicating that all the formulations fulfilled the pharmacopeial limits for weight variation.

The hardness of the compressed chewing gum formulation was found to be in range of 9.8 to $11.7 \mathrm{~kg} / \mathrm{cm}^{2}$. All the formulations were found to conform to pharmacopeial limits of the label claim.

Randomly selected medicated chewing gum formulations passed tests for uniformity of mass with an average mass of $2301.4 \mathrm{mg}$ and non of the formulations were deviated from $\pm 5 \%$ of average mass of chewing gums.

All 10 units of medicated chewing gums from twenty seven formulations, which were sampled randomly, have shown suitable uniformity of content results as contents of BN in all 10 gum fomulations have fallen within a compliance limit of $85-115 \%$ and the average content of BN was found to be $2.98 \mathrm{mg} \pm 0.34 \%$.

In friability test, after 100 rotations, the total weight loss of 10 units of medicated chewing gums were found to be $0.36 \%$ which was less than the compliance limit of $1.0 \%$; so selected gum formulations have passed in the friability test.

As the instrumental settings, the chewing frequency, temperature of the test medium, distance between the upper and lower jaws, and chewing times are four factors which may affect the drug release from the gum base, optimised prior to release test.

Chewing gum formulations containing $\mathrm{BN}$ as active substance were prepared with different ratio of compressible gum base powder, sweetening and co-compressing agents. Within this study, we mainly evaluated the effect of the compressible gum base powder co-compression agents' ratio on in vitro release profile. The rate and amount of drug released from the gum formulations was determined in artificial saliva (pH 6.75), due to the $\mathrm{pH}$ of the saliva is between 6.3 -7.2. Drug release was tested for all formulations that is shown in Table 2 and the mean releasing percentage and the related standard deviations are shown in Figures 1-3.

The release profile obtained after chewing are a proof of the efficiency of this dosage form, as the BN content in the residual gum decreased by increasing the mastication time for all the formulations. Contrary to the expectations, while formulation F7 which is produced with lower amounts of gum base powder and higher amount of aspartame-acesulfame and colloidal silicon dioxide, showed slower release profile; formulation F20 which is prepared with higher amount of gum base powder, showed faster release and released the $65 \%$ of the BN within 5 min. and 96,5\% in 20 min. However, formulation F22 that is prepared with lowest amount of lubricant and high amount of glidant showed the gradually increasing release profile. After 5 min was about $15 \%$ and after 20 min, the release of the BN was reached about 93\%. This finding may propose a longer oral presence of BN in oral cavity as a chewing gum formulation.

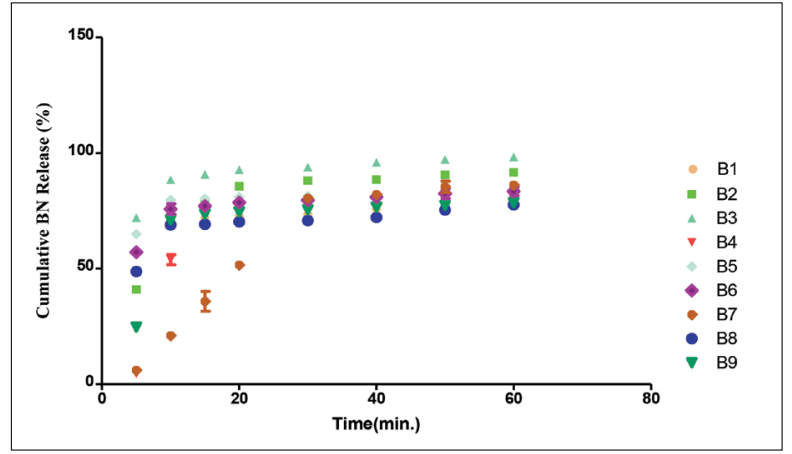

Figure 1. In vitro release profile of $93 \%$ gum base powder containing gum formulations with different ratio of magnesium stearate vs aerosil 200 (Mean SD, $n=3$ )

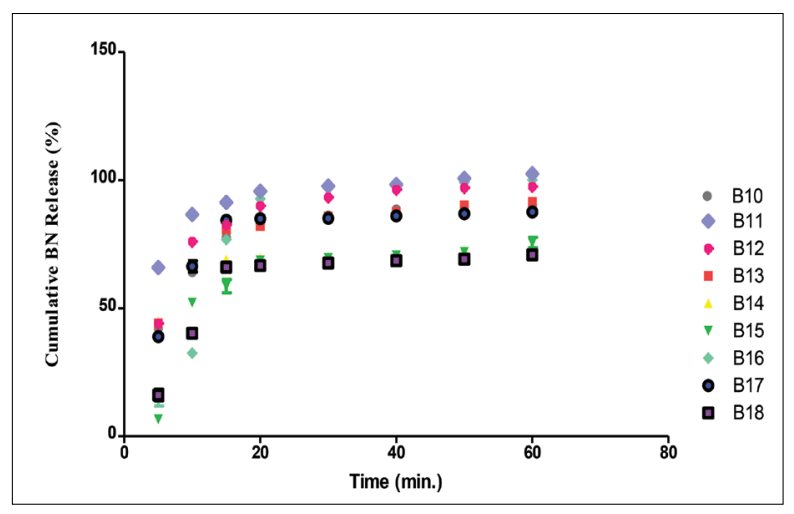

Figure 2. In vitro release profile of $95 \%$ gum base powder containing gum formulations with different ratio of magnesium stearate vs aerosil 200 (Mean SD, $n=3$ )

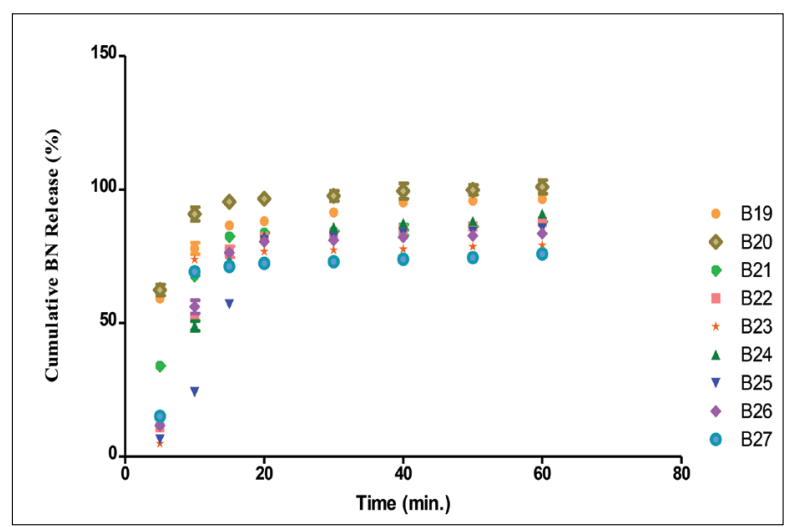

Figure 3. In vitro release profile of $97 \%$ gum base powder containing gum formulations with different ratio of magnesium stearate vs aerosil 200 (Mean SD, n=3)

In all formulations, the determination coefficiency $\left(r^{2}\right)$ values of Korsmeyer Peppas model were close to 1. The diffusion coefficients (n) values ranged from 0.5113 to 0.9988 . Since the $r^{2}$ values of Korsmeyer Peppas matrix were close to 1, the drug release follows matrix diffusion kinetics. Hence it was concluded that diffusion was the mechanism of the drug release from the medicated chewing gums. Further, observed diffusion coefficient values are indicative of the fact that the drug release from the formulation follows non-Fickian transport mechanism. 


\section{Table 3. In vitro Release Kinetics **}

\begin{tabular}{lc}
\hline Mathematical models & Equation \\
\hline Zero order & $F=k_{0} t$ \\
First order & $L n(1-F)=-k_{t} t$ \\
Higuchi & $F=k_{h}{ }^{1 / 2}$ \\
Korsmeyer-Peppas & $F=k_{k}-t^{n}$
\end{tabular}

${ }^{*} \mathrm{~F}$ denotes fraction of drug released up to time $\mathrm{t} . \mathrm{k}_{0}, \mathrm{k}_{\mathrm{t}^{\mathrm{t}}}, \mathrm{k}_{\mathrm{H}}, \mathrm{k}_{1 / 3}, \mathrm{k}_{\mathrm{K}-\mathrm{P}}$ are constant of the mathematical models. $n$ is the release exponent for the Korsmeyer-Peppas model **(Peppas 1985)

These results provide a proof that this dosage form is a good administration system which is able to guarantee a fast and complete drug release after a reasonable chewing time.

\section{DISCUSSION}

At first glance, chewing gums are mainly considered as a confectionery product. However, after medicated chewing gums had become available in the pharmaceutical market, chewing gum paved the way for a more general acceptance as a drug delivery system (Mostafavi et al. 2014). Nowadays, this new drug delivery system has established itself on the market and achieved a reasonable acceptance by both professionals and patients (Rathbone et al. 2002; Rassing et al. 2003). Beside this, when local effect is targetted, chewing gums gain more attention as a drug delivery tool.

Various formulations should be prepared and tested to provide a chewing gum with acceptable organoleptic and technological properties. A pleasant taste is a prerequisite for this dosage form. An optimal chewing volume, a long-lasting taste, antiadherent properties to the teeth, and acceptable pharmaceutical properties such as fast and complete drug release from the prepared formulation must be considered as well (Maggi et al. 2005).

Drug delivery from a medicated chewing gum has completely different dynamics compared to conventional oro-mucosal drug delivery systems. While assesing drug release from chewing gum, chewing activity of the patient should be considered as one of the main factors that has a great influence on drug release. Releasing of the active substance from gum formulation is not performed by disintegrating and/or dissolving by the gum itself, therefore a mechanical treatment of the dosage form is essential.

It is observed from the study that, drug release from the gum to saliva is affected from mechanical forces, temperature, and water permeation. In fact, under sink conditions, the rate of drug release is directly related to the chewing frequency and solubility of drug in buccal cavity and is indirectly related to the mass of the gum base (European Pharmacopoeia, $9^{\text {th }}$ edition). Thus, a specific mastication device was employed for performing drug release to simulate human chewing behavior. However, in some formulations, the co-compression agents caused sandy effect and reduced the chewibility of gum formulations and ratio between the gum base: glidant: lubricant has a great influence on in vitro release profiles of the gum formulations therefore the affect of anti-adherence agents on release profile assesed.

Consequently, F22 formulation which is consist of \%97 gum base, \% 13 BN, \%0,5 magnesium stearate, \%1 Aerosil, \%.0.75 Aspartame-Asesulfam K (1:2) and \%87 menthol, was selected due to its in vitro release profile and in vitro release characteristics.

\section{CONCLUSION}

The study accomplishes the probability of the formulation of the directly compressible chewing gum of BN using Health in Gum (gum base powder) with the improved taste and compressibility by using combination of the sweeteners and cocompression agents. It will give quick analgesic effect. Moreover, it can be taken anywhere anytime without preventing patient from living an active life which promotes very high patient acceptance and higher patient compliance.

\section{Acknowledgements}

This article was resulted from an approved M.Sc. thesis conducted in the Faculty of Pharmacy, İstanbul University. The authors appreciate Istanbul University Science Based Project Department For Research that supported the study financially through research project NO 28948.

\section{REFERENCES}

- $\quad$ Abelson DC, Barton J, Mandel ID (1990). The effect of chewing sorbitol-sweetened gum on salivary flow and cemental plaque pH in subjects with low salivary flow. J Clin Dent 2: 3-5.

- $\quad$ Andersen T, Gram-Hansen M, Pedersen M, Rassing MR (1990). Chewing gum as a drug delivery system for nystatin influence of solubilising agents upon the release of water insoluble drugs. Drug Dev Ind Pharm 16: 1985-1994. [CrossRef]

- Cherukuri SR, Pinney JM, Henningfield JE, Sasan A, Cone EJ, Shiffman S, Gitchell J, Malvestutto CD (2000). Medicated Chewing Gum Delivery System for Nicotine. US Patent No 6344222: 1-24.

- $\quad$ Dodds MWJ, Hsieh SC, Johnson DA (1991). The effect on increased mastication by daily gum-chewing on salivary gland output and dental plaque acidogenicity. J Dent Res 70: 1474-1478. [CrossRef]

- $\quad$ Dong HN, Jabar F, Yilmaz C, Kai PL, DeLuca PP (2005). Chewing gum of antimicrobial decapeptide (KSL) as a sustainedcantiplaque agent. Preformulation study. J Control Release 107: 122130. [CrossRef]

- $\quad$ Eisenstadt B, Cash AP, Bakal IA (1998). Chewing gum containing cough suppression agent. US Patent No 5,846,557.

- $\quad$ European Pharmacopoeia, 9th edition.

- Gajendran J, Kraemer J, Knudsen SR (2008). Product Performance Test for Medicated Chewing Gums.Pharmacopeial Forum 34: 15-18. Herrera D (2005). Efficacy of a $0.15 \%$ benzydamine hydrochloride and $0.05 \%$ cetylpyridinium chloride mouth rinse on 4-day de novo plaque formation. J Clin Periodonto/ 32: 595-603. [CrossRef]

- Kvist LC, Andersson SB, Berglund J, Wennergren B, Fors SM (2000). Equipment for drug release testing of medicated chewing gums. J Pharm Biomed Anal 22: 405-411. [CrossRef]

- Liljewall LR (1992). Apparatus for mechanical processing of a sample and a member of such an apparatus.US Patent No 5,087424. Maggi L, Segale L, Conti S, Ochoa-Machiste E, Salini A, Conte U (2005). Preparation and evaluation of release characteristics of 3TabGum, a novel chewing device. Eur J Pharm Sci 24: 487-493. [CrossRef] 
- Mehta F, Trivedi P (2011). Formulation and texture characterization of medicated chewing gum delivery of dimenhydrinate hydrochloride. Pharm Lett 3:179-192.

- Morjaria M, Irwin WJ, Barnett PX, Chan RS, Conway BR (2009). In vitro release of nicotine from chewing gum formulations. Dissolution Technol 5: 12-15.

- Mostafavi SA, Varshosaz J, Arabian S (2014). Formulation development and evaluation of metformin chewing gum with bitter taste masking. Adv Biomed Res 25: 92. [CrossRef]

- Nagaich U, Chaudhary V, Karki R, Yadav A, Sharma P (2010). Formulation of medicated chewing gum of ondansetron hydrochloride and its pharmacokinetic evaluations. Int J Pharm Sci Res $\mathbf{1}$ 32-40.

- Noehr-Jensen L, Damkier P, Bidstrup TB, Pedersen RS, Nielsen F, Brosen $K$ (2006). The relative bioavailability of loratadine administered as a chewing gum formulation in healthy volunteers. Eur J Clin Pharmacol 62: 437-445. [CrossRef]

- Pedersen M, Rassing MR (1990). Miconazole chewing gum as a drug delivery system application of solid dispersion technique and lecithin. Drug Dev Ind Pharm 16: 2015-2030. [CrossRef]

- Peppas NA. (1985) Analysis of Fickian and non-fickian drug release from polymers. Pharm Acta Helv 60:110-111.

- Rassing MR (1992). Chewing gum as drug delivery system. Adv Drug Deliv Rev 13: 89-121. [CrossRef]

- $\quad$ Rassing MR, Jacobsen J, Nielsen HM (2003). Chewing gum as a drug delivery system. 2th ed, Ellermann Carecom International, Denmark.
- Rathbone MJ, Hadgraft J, Roberts MS (2002). Modified-release drug delivery technology. New York: Marcel Dekker: 1-8. [CrossRef]

- $\quad$ Rowe RC (2003). By gum- a buccal delivery system. Drug Delivery Today 8: 617-618. [CrossRef]

- $\quad$ Stojanov M, Larsen KL (2012). Cetirizine release from cyclodextrin formulated compressed chewing gum. Drug Dev Ind Pharm 38 1061-1067. [CrossRef]

- $\quad$ Swamy NGN, Rupa V, Abbas Z, Dasankoppa FS (2010). Formulation and evaluation of nanosuspensions for enhancing the dissolution of poorly soluble mebendazole. Indian Drugs 47: 47-54.

- Swamy NGN, Shilpa P, Abbas Z (2012). Formulation and characterization of medicated chewing gums of dextromethorphan hydrobromide. Indian Drugs 49: 29-35.

- Testa ES (1999). Medicated chewing gum and process for preparing thereof. US Patent No 5,866,179.

- $\quad$ Tyrpin HT, Russell MP, Witkewitz DL, Johnson SS, Ream RL, Corriveau CL (2002). Caffeine coated chewing gum product and process of making. US Patent No 6444241: 1-15.

- Woodford DW, Lesko LJ (1981). Relative bioavailability of aspirin gum. J Pharm Sci 70:1341-1343. [CrossRef]

- Zyck DJ, Greenberg MJ, Barkalow DG, Marske SW, Schnell PG, Mazzone $P$ (2003). Method of making coated chewing gum products containing various antacids. US Patent No 6645535: 1-14. 